\title{
Reciprocal Homosynaptic and Heterosynaptic Long-Term Plasticity of Corticogeniculate Projection Neurons in Layer VI of the Mouse Visual Cortex
}

\author{
Masoumeh Kourosh Arami, ${ }^{1}$ Kazuhiro Sohya, ${ }^{1,2}$ Abdolrahman Sarihi, ${ }^{1}$ Bin Jiang, ${ }^{1}$ Yuchio Yanagawa, ${ }^{3,4}$ \\ and Tadaharu Tsumoto ${ }^{1}$ \\ ${ }^{1}$ Brain Science Institute RIKEN, Wako, 351-0198 Japan, ${ }^{2}$ PRESTO, Japan Science and Technology Agency, Tokyo, 102-0075 Japan, ${ }^{3}$ Department of Genetic \\ and Behavioral Neuroscience, Gunma University Graduate School of Medicine, Maebashi, 371-8511 Japan, and ${ }^{4}$ CREST, Japan Science and Technology \\ Agency, Tokyo, 102-0075 Japan
}

Most neurons in layer VI of the visual cortex project to the dorsal lateral geniculate nucleus (dLGN). These corticogeniculate projection neurons (CG cells) receive top-down synaptic inputs from upper layers (ULs) and bottom-up inputs from the underlying white matter (WM). Use-dependent plasticity of these synapses in layer VI of the cortex has received less attention than in other layers. In the present study, we used a retrograde tracer injected into dLGN to identify CG cells, and, by analyzing EPSPs evoked by electrical stimulation of the UL or WM site, examined whether these synapses show long-term synaptic plasticity. Theta-burst stimulation induced long-term potentiation (LTP) of activated synapses (hom-LTP) and long-term depression (LTD) of nonactivated synapses (het-LTD) in either pathway. The paired-pulse stimulation protocol and the analysis of coefficient variation of EPSPs suggested postsynaptic induction of these changes except UL-induced het-LTD, which may be presynaptic in origin. Intracellular injection of a $\mathrm{Ca}^{2+}$-chelator suggested an involvement of postsynaptic $\mathrm{Ca}^{2+}$ rise in all types of long-term plasticity. Pharmacological analysis indicated that NMDA receptors and type-5 metabotropic glutamate receptors are involved in WM-induced and UL-induced plasticity, respectively. Analysis with inhibitors and/or in transgenic mice suggested an involvement of cannabinoid type 1 receptors and calcineurin in UL-induced and WM-induced het-LTD, respectively. These results suggest that hom-LTP and het-LTD may play a role in switching the top-down or bottom-up regulation of CG cell function and/or in maintaining stability of synaptic transmission efficacy through different molecular mechanisms.

\section{Introduction}

Visual cortex is a laminated structure consisting of six layers. Neurons in each layer are interconnected in the mainly vertical direction so as to form serial "canonical" circuits (Gilbert, 1983; Thomson and Bannister, 2003; Douglas and Martin, 2004). The bottom layer of the cortex, layer VI, contains a specified type of pyramidal neurons, corticogeniculate neurons (CG cells), which project to the dorsal lateral geniculate nucleus (dLGN) and make up an essential component of corticothalamic feedback circuits (Updyke, 1975; Tsumoto et al., 1978; Bourassa and Deschenes, 1995; for review, see Thomson, 2010). Traditionally the corticothalamic projection is thought to exert facilitatory or suppressive effects on thalamic relay of visual inputs, depending on the spatial alignment between layer VI and dLGN (for review, see Sillito and Jones, 2002). Recently it was reported that CG cells play an im-

\footnotetext{
Received Nov. 19, 2012; revised March 25, 2013; accepted March 25, 2013.

Author contributions: M.K.A. and T.T. designed research; M.K.A., K.S., A.S., B.J., and T.T. performed research;Y.Y. contributed unpublished reagents/analytic tools; M.K.A., K.S., A.S., B.J., and T.T. analyzed data; T.T. wrote the paper.

This work was supported in part by a grant-in-aid for scientific research from the Japan Society for the Promotion of Science to T.T. We thank Dr. A. Miyawaki for providing pCS2-Venus.

The authors declare no competing financial interests.

Correspondence should be addressed to Dr. Tadaharu Tsumoto, Brain Science Institute, RIKEN, 2-1 Hirosawa, Wako 351-0198, Japan. E-mail: tsumoto@brain.riken.jp.

DOI:10.1523/JNEUROSCI.5350-12.2013

Copyright $\odot 2013$ the authors $\quad 0270-6474 / 13 / 337787-12 \$ 15.00 / 0$
}

portant role in gain control of visually evoked responses of cortical neurons mainly through intracortical projections to upper layers (Lee et al., 2012; Olsen et al., 2012).

Regarding synaptic inputs, CG cells receive afferent, bottom-up inputs from dLGN and intracortical, top-down inputs from upper layers, such as layers II/III, IV, and V (Mercer at al., 2005; Zarrinpar and Callaway, 2006; for review, see Thomson, 2010). The activity of CG cells and their function are expected to be regulated by functional plasticity of these converging synaptic inputs through bottom-up and top-down pathways. It is generally thought that cortical circuits are functionally plastic in response to changes in sensory inputs or their own activities. Long-term potentiation (LTP) and long-term depression (LTD) of synaptic transmission are supposed to play a role in such an activity-dependent modification of cortical circuits (for reviews, see Tsumoto, 1992; Bear, 2003; Malenka and Bear, 2004; Smith et al., 2009). Previous studies on LTP and LTD in visual cortex have dealt mostly with synapses on neurons in layers II/III, IV, and V (Komatsu et al., 1981; Artola and Singer, 1987; Kimura et al., 1989; Kirkwood et al., 1993; Dudek and Friedlander, 1996; Heynen and Bear, 2001; Sjöström et al., 2001; Jiang et al., 2007; Cooke and Bear, 2010). While synaptic plasticity in layers II/ III-V of the cortex has been extensively studied, synaptic plasticity of cortical layer VI has not been systematically explored except for two short reports (Wang and Daw, 2003; Petrus et al., 2011). 
Questions of whether bottom-up and top-down synapses on CG cells have the capacity of long-term plasticity, whether there is an interaction between plasticity of convergent synapses, and what mechanisms are involved are important issues for understanding the function of cortical circuits, such as gain control of visual responses of cortical neurons. To our surprise, however, these questions have not been explored previously.

In the present study, we addressed these questions in mice in which CG cells were identified with a retrograde tracer, and found that tetanic stimulation of either pathway induces homosynaptic LTP and heterosynaptic LTD with different induction mechanisms to switch the balance of effects of the two pathways on the function of CG cells.

\section{Materials and Methods}

Preparation of visual cortical slices. Glutamate decarboxylase 67 (GAD67)-green fluorescent protein (GFP) ( $\Delta$ neo) knock-in mice (Sohya et al., 2007), or vesicular GABA transporter (VGAT)-Venus transgenic mice (Kameyama et al., 2010) of either sex, aged from postnatal day (P) 19 to P26, were anesthetized with isoflurane (Abbott) and then decapitated. In some experiments, type 1 of cannabinoid receptor $\left(\mathrm{CB}_{1} \mathrm{R}\right)$-knock-out (CB-KO) mice were used (Zimmer et al., 1999). Breeding pairs of CB-KO mice were kindly provided by M. Kano (Tokyo University, Japan) under an agreement of A. Zimmer (University of Bonn, Germany). The brains were rapidly removed and placed in the cold oxygenated artificial CSF (ACSF). Coronal slices of the visual cortex (300 $\mu \mathrm{m}$ thick) were obtained using a tissue slicer (Vibratome 3000, Vibratome). All experimental procedures were performed in accordance with the guidelines of the Animal Experimental Committee of RIKEN Brain Science Institute. Slices were placed in an incubating chamber of oxygenated ACSF for at least $1 \mathrm{~h}$ before recording. The incubating and recording temperature was $30^{\circ} \mathrm{C}$. The ACSF had the following composition (in mM): $124 \mathrm{NaCl}, 3 \mathrm{KCl}, 2 \mathrm{CaCl}_{2}, 1 \mathrm{MgCl}_{2}, 1.25 \mathrm{NaH}_{2} \mathrm{PO}_{4}, 26$ $\mathrm{NaHCO}_{3}$, and 10 glucose, $\mathrm{pH}$ 7.4. The ACSF was bubbled continuously with $95 \% \mathrm{O}_{2}$ and $5 \% \mathrm{CO}_{2}$. The flow rate of the ACSF was $\sim 2.5 \mathrm{ml} / \mathrm{min}$.

Retrograde labeling of corticogeniculate projection cells. Mice anesthetized with ketamine $(100 \mathrm{mg} / \mathrm{kg}$, i.m.) and xylazine $(10 \mathrm{mg} / \mathrm{kg}$, i.m.) were fixed in a stereotaxic head holder. Throughout the experiment, the core body temperature, measured with a rectal probe, was maintained at $37^{\circ} \mathrm{C}$ by using a thermostatically controlled electrical blanket (NP 50-7061-R, Harvard Apparatus). A circular craniotomy $\sim 0.5 \mathrm{~mm}$ in diameter was made unilaterally above the assumed location of the dLGN, $\sim 2.5 \mathrm{~mm}$ posterior to the bregma and $2 \mathrm{~mm}$ lateral from the midline. A small duratomy was made in the center of this exposed area, and a tungstenin-glass electrode (Alan Ainsworth, Northants, United Kingdom) was lowered vertically into the brain using a micromanipulator. Multiunit signals were amplified with a differential amplifier (DAM 80, WPI). Background multiunit activities evoked by flash light stimuli given to the contralateral eye were monitored while advancing the microelectrodes through the brain. When the tip of the electrode reached the dLGN at the depth of 2.5-3.0 mm from the cortical surface, brisk, reliable visual responses were obtained. Then, we injected 170-200 nl of Alexa Fluor 555-conjugated cholera toxin subunit B (CTB555, Invitrogen) into the dLGN through glass pipettes by pressure (PV820, WPI). Five to seven days after the tracer injection, cortical slices $300 \mu \mathrm{m}$ thick were made from the visual cortex in the same way as mentioned above. Then, the sections containing the injection site and layer VI of the visual cortex were observed with a confocal microscope (FV 1000-D, Olympus) with excitation wavelength of $488 / 515 \mathrm{~nm}$ and emission filter of 500-530/ $530-545 \mathrm{~nm}$ for GFP/Venus fluorescence and excitation wavelength of $559 \mathrm{~nm}$ and emission filter of $600-700 \mathrm{~nm}$ for Alexa Flour 555-CTB.

Stimulating electrodes and whole-cell recordings. Whole-cell recordings from CG or non-CG pyramidal neurons in layer VI of visual cortical slices were performed under infrared differential interference contrast optics. Two stimulating electrodes of the concentric bipolar type (diameter, $125 \mu \mathrm{m}$; FHC) were placed in layer II/III near the border of layer IV and at the site in the white matter (WM) $\sim 200 \mu \mathrm{m}$ beneath the recorded cells. EPSPs evoked by test stimulation given to the two sites alternatively at $0.1 \mathrm{~Hz}$ (at $0.05 \mathrm{~Hz}$ to each site) were recorded in the current-clamp mode using a multiclamp amplifier (700B, Molecular Devices), filtered at $2-5 \mathrm{kHz}$, digitized at $10 \mathrm{kHz}$, and fed into a Pentium 4 personal computer with a digitizer computer interface (PCI-MIO-16E-4, National Instruments). Data analysis was performed using the Igor 4.01 program.

Recording electrodes were pulled from borosilicate glass capillary with filaments (inner diameter, $0.86 \mathrm{~mm}$; outer diameter, $1.5 \mathrm{~mm}$ ). The resistance of these electrodes with the following internal solution was 4-6 $\mathrm{M} \Omega$. The composition of the internal solution was as follows (in $\mathrm{mM}$ ): $130 \mathrm{~K}$-gluconate, $10 \mathrm{KCl}, 10 \mathrm{HEPES}, 0.2 \mathrm{EGTA}, 4 \mathrm{MgATP}, 0.5 \mathrm{Na}_{3} \mathrm{GTP}$, and $10 \mathrm{Na}$-phosphocreatine, adjusted to $\mathrm{pH} 7.4$ with $\mathrm{KOH}$. The osmolarity of the solution was 275-290 mOsm. The input resistance of neurons was continuously monitored throughout recordings by injecting hyperpolarizing test currents ( $-20 \mathrm{pA}$ for $100 \mathrm{~ms}$ ). The measured values were generally $80-150 \mathrm{M} \Omega$, and usually very stable during recordings. If these values changed $>20 \%$, recordings were stopped and the data were discarded. In the experiments in which postsynaptic $\mathrm{Ca}^{2+}$ was chelated, 1,2-bis-(2-aminophenoxy)ethane- $N, N, N^{\prime}, N^{\prime}$-tetra-acetic acid (BAPTA) was added at the concentration of $10 \mathrm{~mm}$ to the internal solution of recording electrodes.

Induction of homosynaptic LTP and heterosynaptic LTD. After recording baseline responses evoked by test stimulation (pulse of $0.1 \mathrm{~ms}$ duration) for $10 \mathrm{~min}$, theta-burst stimulation (TBS) paired with postsynaptic depolarization at $0 \mathrm{mV}$ for $40 \mathrm{~s}$ was applied to one of the two stimulation sites. TBS consisted of five trains at $0.1 \mathrm{~Hz}$, each train consisting of 10 bursts at $5 \mathrm{~Hz}$, and each burst consisting of four pulses at $100 \mathrm{~Hz}$. The intensity of test stimulation was set at 1.5-2.0 times the threshold for eliciting detectable responses (30-80 $\mu \mathrm{A}$ for pulses of $0.1 \mathrm{~ms}$ duration), and the intensity and width of each pulse of TBS were the same as those of 

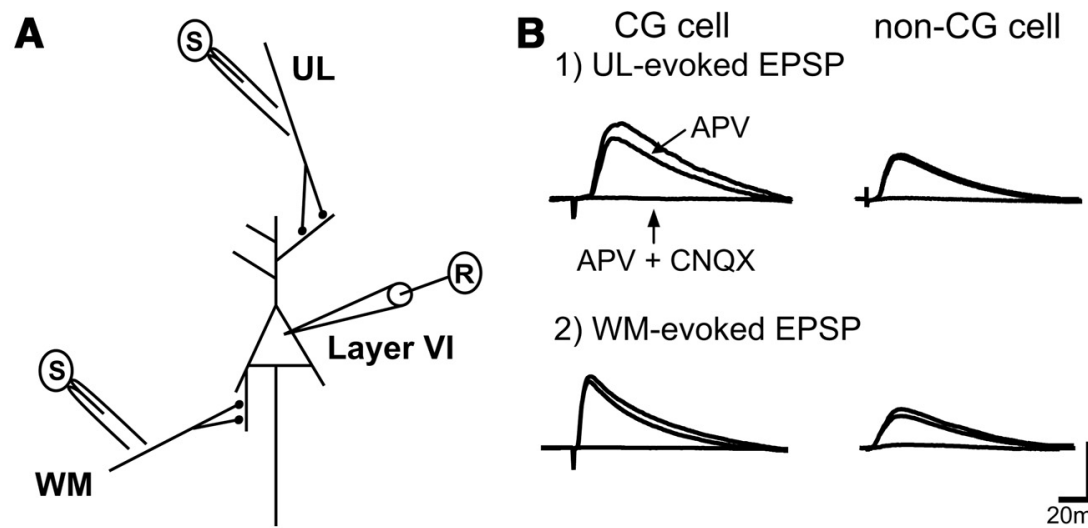

2) WM-evoked EPSP

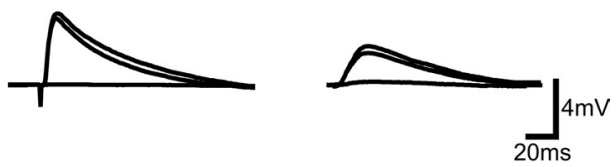

C

UL-evoked EPSP

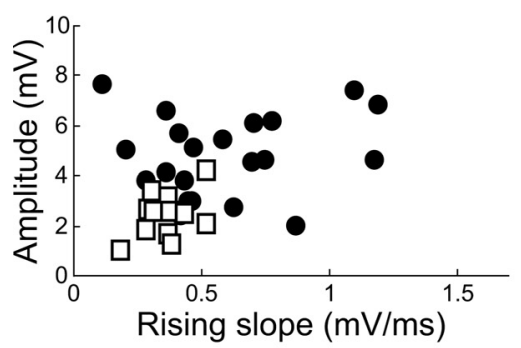

D

WM-evoked EPSP

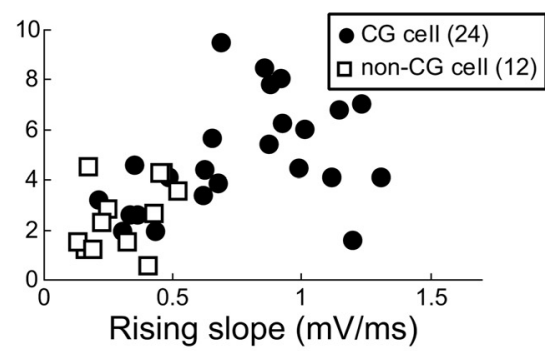

$\mathbf{F}$

$\mathbf{E}$

U, W: UL-, WM-evoked EPSPs

1) Paired-pulse stimulation $\bigwedge_{1}^{u 2}$

2) Alternative stimulation
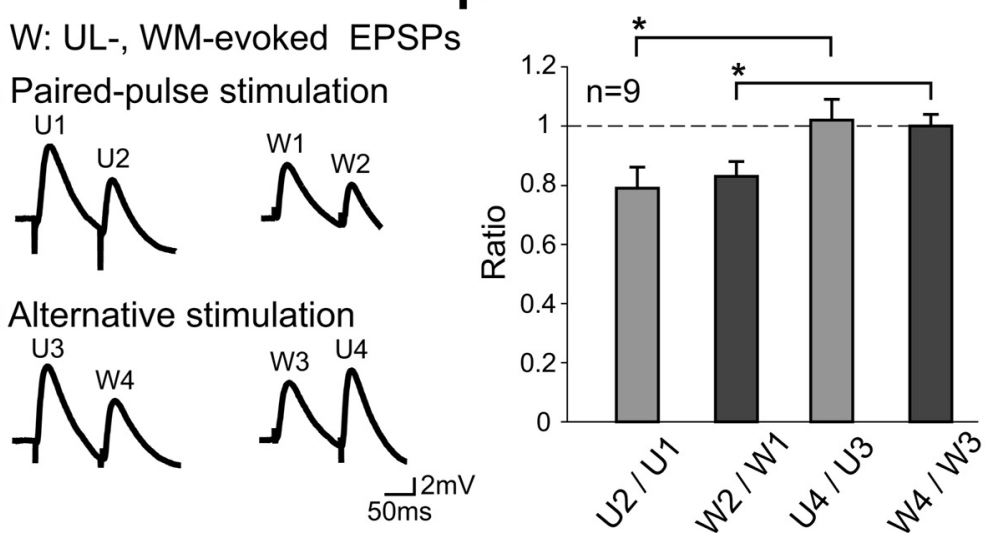

Figure 2. EPSPs recorded from CG and non-CG cells in cortical layer VI in response to stimulation of the UL and WM sites. $\boldsymbol{A}$, Arrangement of stimulating and recording electrodes in visual cortical slices. $\boldsymbol{B}$, Examples of EPSPs of a layer VI CG cell (left column) and a non-CG cell (right column) evoked by test stimulation of the UL (1) and WM (2) sites without any drug (top traces), with APV (middle traces) and APV plus CNQX (bottom traces). Scales at bottom right apply to all records. C, The peak amplitude of UL-evoked EPSPs is plotted against their rising slope for 24 CG cells (filled circles) and 12 non-CG cells (open squares) in cortical layer VI. D, The peak amplitude of WM-evoked EPSPs is plotted against their rising slope for the CG cells and non-CG cells in layer VI. The other conventions are the same as in C. E, EPSPs evoked by paired pulses applied to the same site at an interval of $100 \mathrm{~ms}$ (1). EPSPs evoked by stimulation given to the two different sites alternately at an interval of $100 \mathrm{~ms}$ (2). U1 to U4 indicate EPSPs evoked by test stimulation of the upper layer site. Also W1 to W4 indicate EPSPs evoked by test stimulation of the WM site. Scales at bottom right apply to all of the records. $\boldsymbol{F}$, Mean ratios of the amplitudes of the second EPSPs to the first ones evoked by two successive stimulations, as indicated at the abscissa. The vertical bars indicate SEM.

the test pulse. Thereafter, responses to test stimulation at $0.05 \mathrm{~Hz}$ were recorded again for at least $30 \mathrm{~min}$. During TBS, the membrane potentials were clamped at $0 \mathrm{mV}$ in the voltage-clamp mode. After TBS, the recordings were performed in the current-clamped mode again.

Drugs. Drugs were applied through the perfusion medium. The medium containing drugs at given concentrations was prepared with ACSF or dimethyl sulfoxide (DMSO) $(0.1 \%$ in ACSF). It is reported that this concentration of DMSO has no effect on excitatory synaptic transmission in the mouse visual cortex (Sarihi et al., 2008). Interleaved control recordings were performed in non-drug-treated slices from the same animals. As selective antagonists for the respective type of glutamate receptors, we used the following drugs: D,L-2-amino-5-phosphonovaleric acid (APV; Sigma-Aldrich) at $100 \mu \mathrm{M}$ for NMDA receptors, 6-cyano-7-nitroquinoxaline2,3-dione (CNQX; Sigma-Aldrich) at $20 \mu \mathrm{M}$ for AMPA receptors, 2-methyl-6-(phenylethynyl)pyridine hydrochloride (MPEP; Tocris Bioscience) at $10 \mu \mathrm{M}$ for the type 5 of mGluRs (mGluR5) and (s)-(+)- $\alpha$-amino-4-carboxy-2methylbenzeneacetic acid (LY367385; Tocris Bioscience) at $100 \mu \mathrm{m}$ for mGluR1. As the selective agonist and antagonist for $\mathrm{CB}_{1} \mathrm{R}$, we used R-(+)-(2,3-dihydro-5-methyl-3-[(4-morpholinyl)methyl]pyrol[1,2,3-de]-1,4-benzoxazin-6yl) (1-naphthalenyl) methanone mesylate [WIN55,212-2 (WIN); Tocris Bioscience] at 2 $\mu \mathrm{M}$, and $\mathrm{N}$-(piperidin-1-yl)-5-(4-iodophenyl)1-(2,4-dichlorophenyl)-4-methyl-1H-pyrazole3-carboxamide (AM251; Tocris Bioscience) at 5 $\mu \mathrm{M}$, respectively. As a selective inhibitor for calcineurin, FK-506 (Cayman Chemical) was dissolved in $100 \%$ methanol and then diluted with ACSF. The final concentration of FK-506 was 1 $\mu \mathrm{M}$ and that of methanol was $0.01 \%$. This concentration of methanol was reported to have no effect on field responses of rat visual cortex (Funauchi et al., 1994).

Statistical analysis. In the present study, values are given as mean \pm SEM, unless otherwise mentioned. For statistical analysis, values before and after TBS obtained from the same cell and values between two groups of cells were compared by the paired and unpaired $t$ tests, respectively, when values showed normal distribution. The statistical evaluation of normal distribution was performed using the Kolmogorov-Smirnov test.

\section{Results}

Identification of CG cells

To identify cortical neurons that project to dLGN (CG cells), we injected Alexa Fluor 555-conjugated cholera toxin subunit $B$ as a retrograde tracer into the dLGN of VGAT-Venus or GAD67-GFP mice 5-7 d before recording experiments (Fig. 1A). As shown in Figure $1 B, C$, neurons located in the upper part of layer VI of the primary visual cortex had fluorescence of Alexa. None of the cells containing Alexa (in red) overlapped with GABAergic neurons expressing GFP or Venus signals (in green), indicating that this retrograde tracer marked only projection neurons.

From Alexa-positive CG cells and Alexa-negative non-CG pyramidal cells in layer VI of the visual cortex, we recorded EPSPs evoked by test stimulation given to the upper layers (ULs) and the underlying WM (UL-evoked and WM-evoked EPSPs, respectively; Fig. $2 A, B$ ). If stimulation of the WM site generated antidromic action potentials, the location of the stimulating electrode was slightly shifted or the intensity of stimulation was changed so as to induce EPSPs alone. Both UL-evoked and WMevoked EPSPs were slightly depressed by an application of APV $(\sim 10-20 \%$ reduction in the amplitude) and almost completely blocked by the simultaneous application of CNQX and APV (Fig. 
Table 1. Properties of EPSPs evoked by stimulation of the UL and WM sites

\begin{tabular}{|c|c|c|c|c|}
\hline & Onset latency (ms) & Peak amplitude (mV) & Rising slope (mV/ms) & Decay time (ms) (peak to 63\%) \\
\hline \multicolumn{5}{|l|}{ CG cell $(n=24)$} \\
\hline UL-evoked EPSP & $4.01 \pm 0.16]$ & $4.75 \pm 0.36]^{* * * *}$ & {$[0.57 \pm 0.06]^{* *}$} & $16.77 \pm 0.59]$ \\
\hline WM-evoked EPSP & $2.69 \pm 0.22]^{* * *}$ & $4.80 \pm 0.47$ & $*[0.77 \pm 0.05] 1$ & $14.65 \pm 0.64]^{*}$ \\
\hline \multicolumn{5}{|l|}{ Non- $\mathrm{CG}$ cell $(n=12)$} \\
\hline UL-evoked EPSP & $4.81 \pm 0.31]$ & $2.47 \pm 0.28 d \int_{* * *}$ & $0.35 \pm 0.02]]_{* * *}$ & $14.72 \pm 2.20$ \\
\hline WM-evoked EPSP & $3.22 \pm 0.50]^{*}$ & $2.52 \pm 0.39]$ & $0.31 \pm 0.03]$ & $13.36 \pm 0.81$ \\
\hline
\end{tabular}

$*^{* * *}$, and ${ }^{* * *}$ indicate statistically significant difference at $p<0.05,0.01$, and 0.001 , respectively.

$2 B)$, confirming that they were EPSPs mediated mostly through the AMPA type of glutamate receptors. These EPSPs were judged as monosynaptically induced, based on short onset latencies (Table 1) and very small jitters. The jitters of the latencies were $<0.5 \mathrm{~ms}$ for all groups of EPSPs. As seen in Figure $2 B$, EPSPs evoked by stimulation of the two different sites showed different properties. In most CG cells, UL-evoked EPSPs had longer onset latency, slower rising slope, and slower decay time than those of WM-induced EPSPs (Table 1).

We also found that there were significant differences in EPSP properties between CG cells and non-CG cells, regardless of stimulation site. The mean peak amplitude of UL-evoked and WMevoked EPSPs for the non-CG cells was significantly (both, $p<0.001$, unpaired $t$ test) lower than those of the respective EPSPs of the CG cells (Table 1; Fig. 2C,D). Also, the rising slopes of both types of EPSPs of the non-CG cells were much smaller $(p<0.01$ and 0.001, unpaired $t$ test) than the respective values of the CG cells (Table 1; Fig. 2C,D). Regarding the intrinsic membrane properties of cells, such as resting membrane potential and input resistance, there were no significant differences between CG and non-CG cells. The resting membrane potentials and input resistances of the 24 CG cells were $-64 \pm 1.1 \mathrm{mV}$ and $124 \pm 5.2 \mathrm{M} \Omega$ while those of the 12 non-CG cells were $-68 \pm 1.0 \mathrm{mV}$ and $124 \pm 13.6 \mathrm{M} \Omega$, respectively. In layer VI of the visual cortex, only approximately one-third of pyramidal cells were assumed to be non-CG cells based on the sampling number of cells. This seems consistent with a recent report that $67-68 \%$ of cells labeled with two different retrograde tracers are corticothalamic cells and 31$32 \%$ of the labeled cells are interareal corticocortical cells in layer VI of the somatosensory, auditory, and visual cortices of the mouse, although corticocortical projection within the same area was not included (Petrof et al., 2012). Non-CG cells were not further analyzed in the present study because they were the minority of cells in layer VI of the mouse visual cortex. CG cells were analyzed as a group, although this cell population may potentially be composed of multiple subtypes (Tsumoto and Suda, 1980; Swadlow and Weyand, 1987; Briggs and Usrey, 2007).

\section{A UL-induced changes}
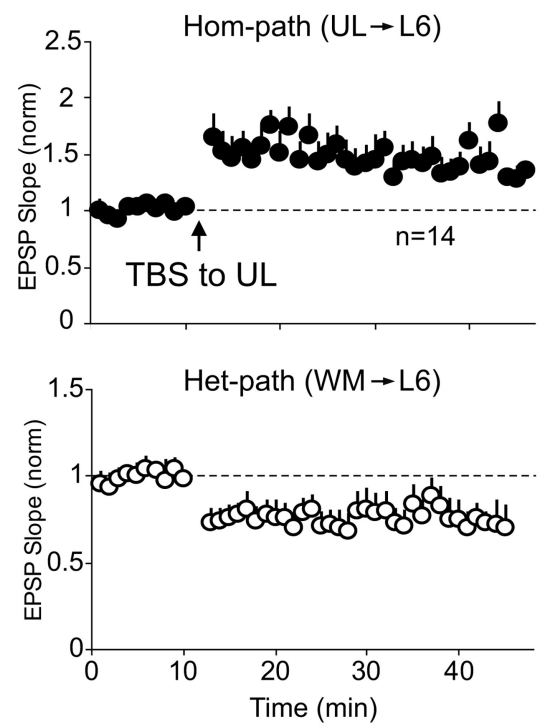

B Magnitude of changes (TBS to UL)

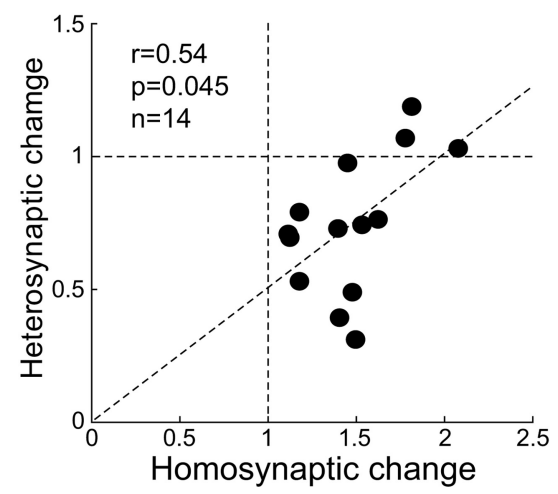

Figure 3. Induction of hom-LTP and het-LTD and relationship between their magnitudes. $\boldsymbol{A}$, Hom-LTP ofUL-evoked EPSPs (top) and het-LTD of WM-evoked EPSPs (bottom) induced by TBS of the UL site. The means of EPSP slopes normalized to the control values $10-0 \mathrm{~min}$ before TBS for 14 cells are plotted against time. Circles and vertical bars indicate means \pm SEMs. SEMs smaller than circles are not shown. $B$, Relationship between the magnitudes of hom-LTP and het-LTD induced by TBS of the UL site. Dotted oblique line indicates regression line. The $r$ value, $p$ value, and the number of cells are indicated at top left. $\boldsymbol{C}$, Hom-LTP of WM-evoked EPSPs (top) and het-LTD of UL-evoked EPSPs (bottom) induced by TBS of the WM site. Other conventions are the same as in $\boldsymbol{A}$ except for the number of cells. $\boldsymbol{D}$, Relationship between the magnitude of hom-LTP and het-LTD induced by TBS of the WM site. Other conventions are the same as in $\boldsymbol{B}$.

To confirm that the two pathways (UL $\rightarrow$ layer VI and $\mathrm{WM} \rightarrow$ layer VI) were separately activated, we used the pairedpulse and primed-pulse stimulation protocol. Initially, paired pulses at an interval of $100 \mathrm{~ms}$ were applied to the UL and WM sites, respectively. As shown in Figure $2 E$ (1) the second responses were smaller than the first responses at both pathways. The mean paired-pulse ratios (PPRs) of the UL-evoked and WMevoked EPSPs were $0.79 \pm 0.07$ and $0.83 \pm 0.05$, respectively (Fig. 
$2 F)$. Thus, paired-pulse depression was induced at both pathways. Then, the first and second stimuli were applied to the UL and WM sites, or the WM and UL sites, respectively. As shown in Figure $2 E$ (2), the second responses (W4 and U4) were not smaller than the first responses at the corresponding sites (W3 and $\mathrm{U} 3$, respectively), indicating that the first stimuli did not affect the responses to the second stimuli. This was confirmed in the group analysis of ratios of the peak amplitude of the second responses to that of the first responses (Fig. $2 \mathrm{~F}$, right 2 columns). The mean ratios of the EPSP amplitudes of U4 to U3 and W4 to $\mathrm{W} 3$ were $1.02 \pm 0.07$ and $1.00 \pm 0.04$, respectively. These values were nearly 1.0 and significantly $(p<0.05)$ different from those of $\mathrm{U} 2$ to $\mathrm{U} 1$ and $\mathrm{W} 2$ to $\mathrm{W} 1$. These results indicate that test stimulation of one site did not concomitantly activate the other site.

\section{Induction of homosynaptic LTP and heterosynaptic LTD in both pathways}

To examine whether TBS of one pathway induces long-lasting changes in excitatory synaptic transmission in the activated pathway (called homosynaptic pathway) and the other, nonactivated pathway (called heterosynaptic pathway), we initially applied test stimuli to the UL and WM sites alternately every $10 \mathrm{~s}(0.05 \mathrm{~Hz}$ at each site) and recorded baseline EPSPs from CG cells, and then applied TBS to either site. An application of TBS to the UL site induced a robust and immediate enhancement of EPSPs in the homosynaptic pathway (Fig. $3 A$, top). This enhancement lasted for all the recording time (35 min after stopping TBS) and thus this LTP was called homosynaptically induced LTP (hom-LTP). In the 14 CG cells, the mean ratio of the UL-evoked EPSP slope 20-25 min after TBS to that before TBS was $1.42 \pm 0.02$, which was significantly $(p<0.05)$ larger than the baseline value. Simultaneously long-lasting depression was induced in the WMevoked EPSPs (Fig. 3A, bottom). The WM was not activated by TBS, and thus this LTD was called heterosynaptically induced LTD (het-LTD). In the 14 cells, the mean ratio of the WM-evoked EPSP slope 20-25 min after TBS to that before TBS was $0.78 \pm$ 0.03 , which was significantly $(p<0.05)$ smaller than the baseline value. Then we tested whether the magnitude of hom-LTP is related to that of het-LTD in the 14 cells. As shown in Figure $3 B$, there was a weak negative correlation $(p=0.045)$ between the magnitudes of the homosynaptic and heterosynaptic changes.

Then we applied TBS to the WM site, which also induced hom-LTP and het-LTD (Fig. 3C). In the 11 CG cells, the mean ratio of the WM-evoked EPSP slope 20-25 min after TBS to that before TBS was $1.63 \pm 0.03$, which was significantly $(p<0.05)$ larger than the baseline value. Simultaneously, het-LTD was induced in the UL-evoked EPSPs (Fig. 3C, bottom). In the $11 \mathrm{CG}$ cells, the mean ratio of the UL-evoked EPSP slope 20-25 min after TBS to that before TBS was $0.65 \pm 0.01$, which was significantly $(p<0.05)$ smaller than the baseline value. Again we examined the possibility that the magnitude of hom-LTP is related to that of het-LTD. As shown in Figure 3D, a weak negative correlation ( $p=0.041$ ) was seen between the magnitudes of the homosynaptic and heterosynaptic changes after TBS of the WM site.

Het-LTD induced by TBS of the UL site may be presynaptic, whereas the other long-term changes may be postsynaptic To address the question whether the induced long-term changes are presynaptic or postsynaptic in origin, we initially applied the paired-pulse stimulation protocol. The ratios of the amplitudes of the second EPSPs to those of the first EPSPs were calculated in the CG cells that showed significant hom-LTP or het-LTD. In the

\section{A Paired-pulse ratio before and after hom-LTP}
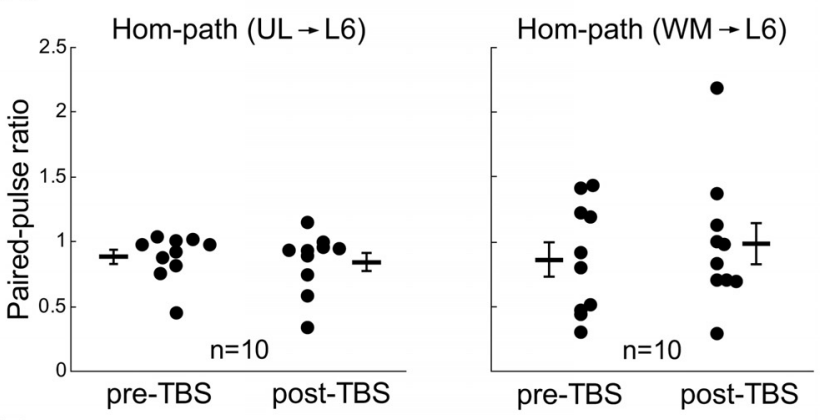

B Paired-pulse ratio before and after het-LTD
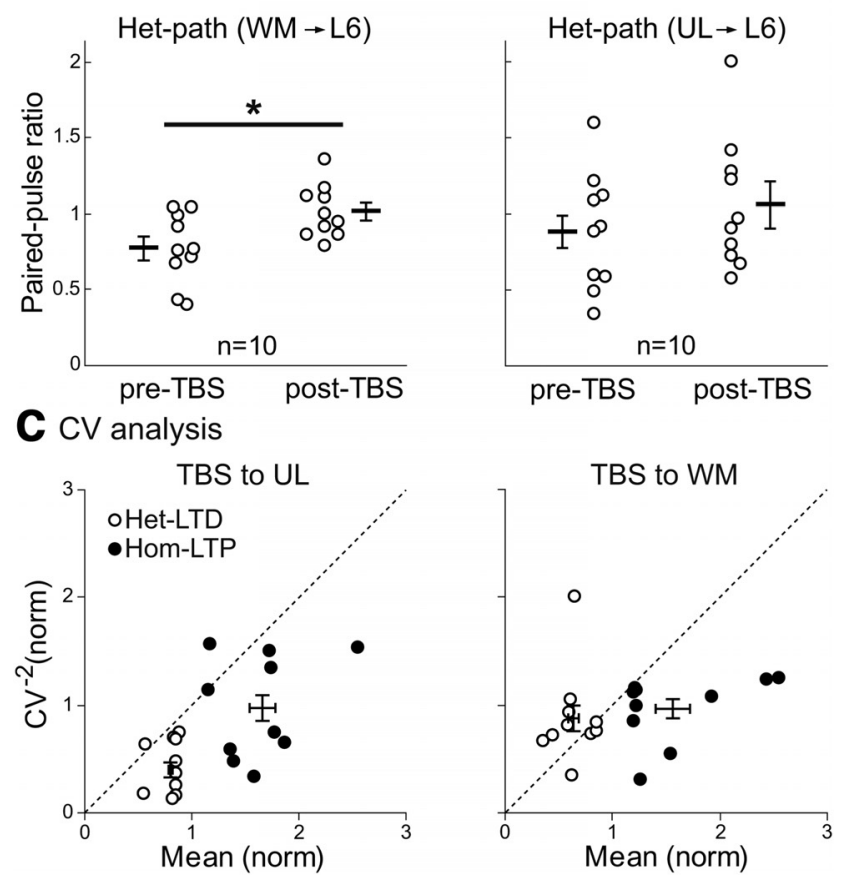

Figure 4. Paired-pulse ratio and CV analysis of changes in EPSPs. A, Paired pulse ratio of EPSPs evoked by stimulation of the UL site (left) and the WM site (right) before and after the induction of hom-LTP. The mean \pm SEM of the ratios of UL-evoked EPSPs before and after TBS were $0.87 \pm 0.04$ and $0.84 \pm 0.06$, respectively (left graph). Those of WMevoked EPSPs before and after TBS were $0.86 \pm 0.13$ and $0.98 \pm 0.16$, respectively (right). $B$, Paired pulse ratio of EPSPs evoked by stimulation of the WM site (left) and the UL site (right) before and after the induction of het-LTD. The mean \pm SEM of the ratios of WM-evoked EPSPs before and after TBS were $0.77 \pm 0.08$ and $1.01 \pm 0.05$, respectively (left). Those of UL-evoked EPSPs before and after TBS were $0.88 \pm 0.10$ and $1.05 \pm 0.15$, respectively (right). ${ }^{*} p<0.05$. C, CV analysis of changes in the amplitude of EPSPs after the induction of hom-LTP (filled circles) and het-LTD (open circles) by TBS of the UL site (left) and of the WM site (right). Ten cells that showed significant hom-LTP and het-LTD were selected for this analysis. Long horizontal bars and vertical bars indicate mean \pm SEMs. Left, Mean normalized values of $\mathrm{CV}^{-2}$ for het-LTD and hom-LTP by TBS of the UL site were $0.40 \pm 0.07$ and $0.98 \pm 0.12$, and the normalized mean value were $0.80 \pm 0.02$ and $1.66 \pm 0.12$, respectively. Right, Values for het-LTD and hom-LTP by TBS of the WM site were $0.88 \pm 0.12$ and $0.97 \pm 0.09$ for the normalized value of $\mathrm{CV}^{-2}$ and $0.64 \pm 0.05$ and $1.57 \pm 0.16$ for the normalized mean value, respectively.

10 cells that showed significant hom-LTP of UL-evoked EPSPs, the mean PPR was not significantly changed after TBS of the UL site (Fig. 4A, left). Also, in another 10 CG cells that showed significant hom-LTP of WM-evoked EPSPs, the mean PPR value was not significantly changed after the induction of hom-LTP (Fig. $4 A$, right). On the other hand, the mean PPR value of WMinduced EPSPs of the 10 cells that showed het-LTD was significantly ( $p<0.05$, paired $t$ test) increased after the LTD induction, 
suggesting that the probability of presynaptic transmitter release to test stimulation may be decreased (Fig. 4B, left). Different from such a change, the mean PPR of UL-evoked EPSPs was not significantly changed after the induction of hetLTD by TBS of the WM site (Fig. $4 B$, right). These results suggest that het-LTD induced by TBS of the UL site may be presynaptic, while the other types of longterm changes may be postsynaptic in origin.

To confirm this suggestion, we next performed the coefficient of variation (CV) analysis (Faber and Korn, 1991; Sjöström et al., 2003). On the basis of a binomial model of synaptic transmission, functional changes in presynaptic sites are expected to be accompanied by a change in the CV of synaptic responses: the values of $\mathrm{CV}^{-2}$ plotted against the change in efficacy should be located on or below the diagonal line, if the release probability is low. On the other hand, if changes are located purely in postsynaptic sites, the values should be located on the horizontal line of 1.0. As shown in Figure 4C (left), the values of all but 1 of 10 neurons that showed het-LTD (open circles) by TBS of the UL site were located below the diagonal line. The exception was above but very close to the line. Meanwhile, the values of the cells that showed hom-LTP (filled circles) were located around the normalized $\mathrm{CV}^{-2}$ value of 1.0 (mean \pm SEM, $0.98 \pm$ 0.12 ). Similarly the values of the cells that showed hom-LTP by TBS of the WM site (Fig. 4C, right, filled circles) were located around the normalized $\mathrm{CV}^{-2}$ value of 1.0 $(0.97 \pm 0.09)$. The mean value of the cells that showed het-LTD by TBS of the WM site (Fig. $4 C$, right, open circles) was close to the value of $1.0(0.88 \pm 0.12)$, although four cells were located below or on the diagonal line. These results confirmed that het-LTD and hom-LTP induced by TBS of the UL site may be presynaptic and postsynaptic in origin, respectively (see Fig. 9), whereas both het-LTD and homLTP by TBS of the WM site may be mostly postsynaptic in origin, although we cannot completely exclude the mixed presynaptic and postsynaptic changes in a fraction of these cells.

Hom-LTP and het-LTD induced by TBS of the WM site are NMDA receptor-dependent, whereas those by TBS of the UL site are not

It is well known that an activation of NMDA receptors is necessary to induce hom-LTP at excitatory synapses of layer II/III pyramidal cells in the visual cortex (Artola and Singer, 1987; Kimura et al., 1989). In the present study, we used an antagonist for NMDA receptors, APV, to examine whether NMDA receptors are also involved in the induction of hom-LTP and het-LTD the same as in $\boldsymbol{A}$.

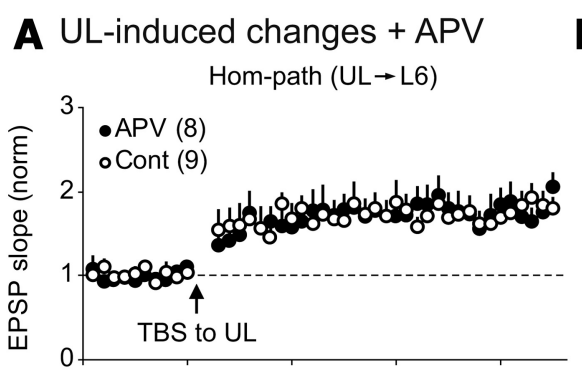
B WM-induced changes + APV
Hom-path $(\mathrm{WM} \rightarrow \mathrm{L6}$ )
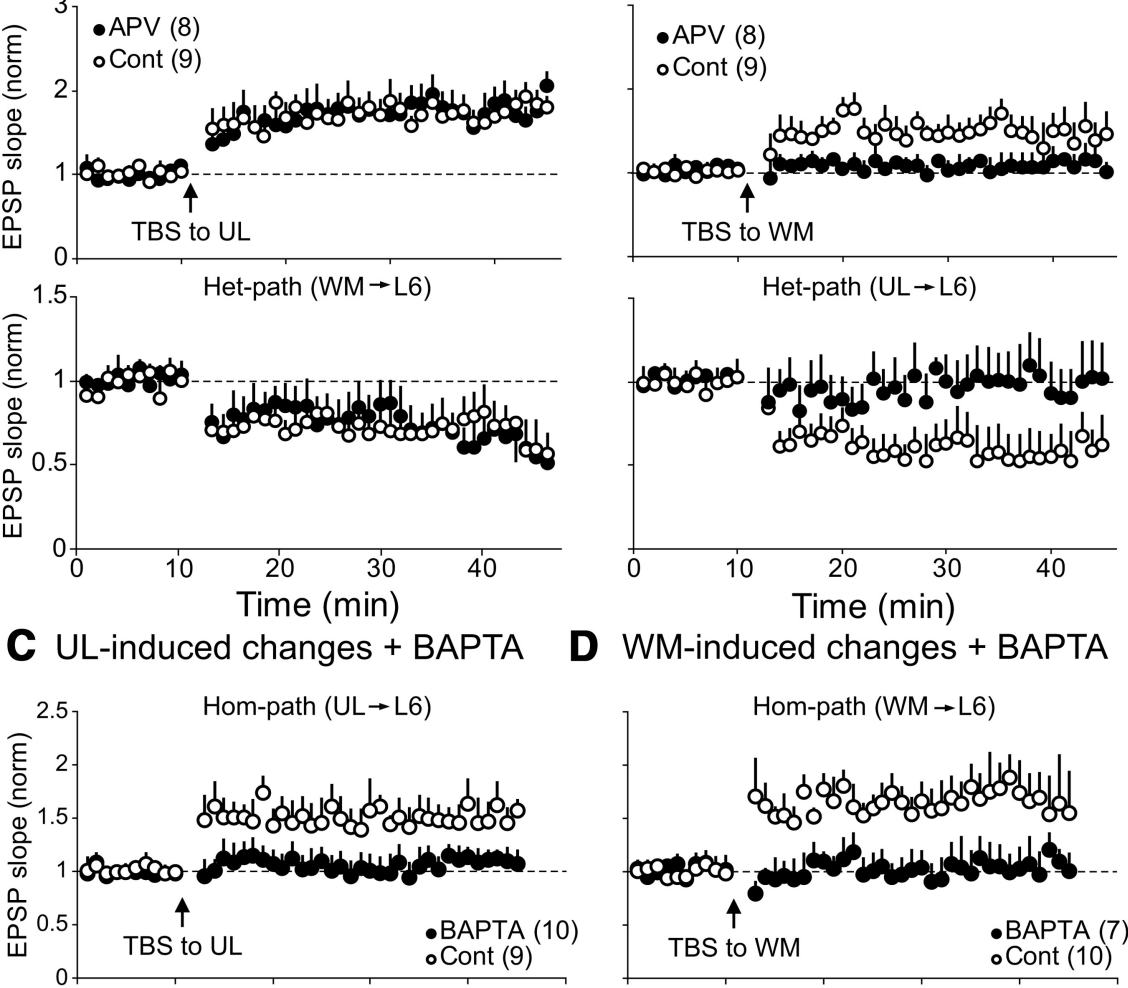

WM-induced changes + BAPTA
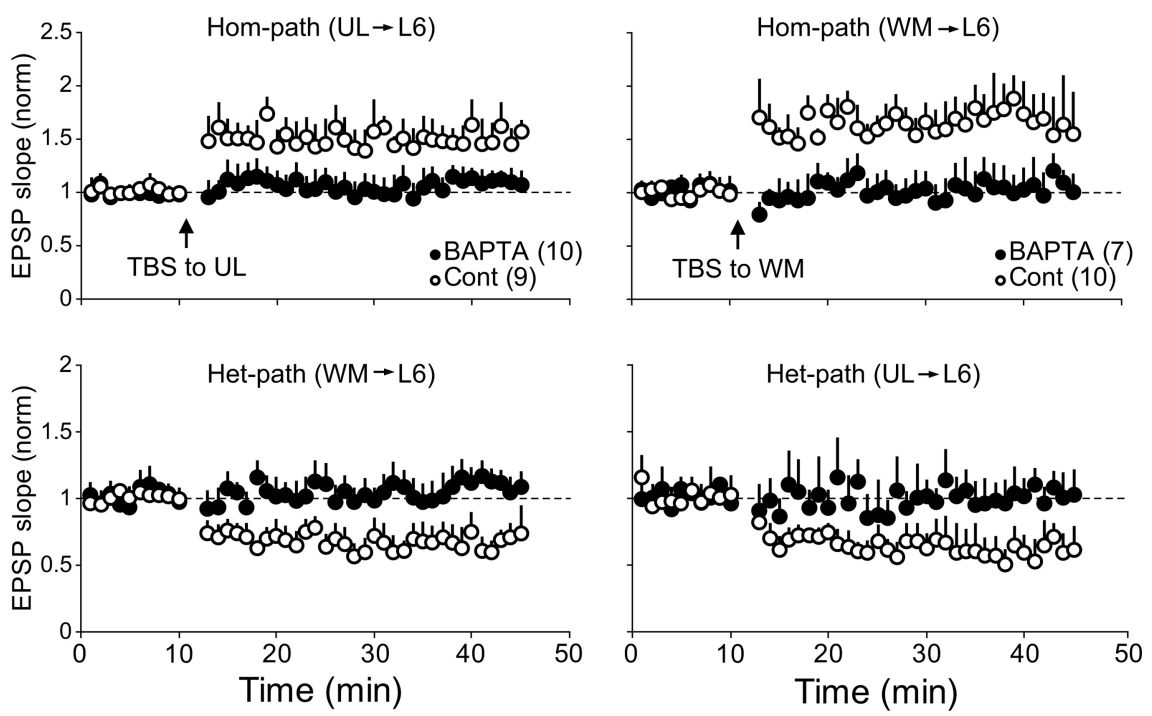

Figure 5. Selective involvement of NMDA receptors and blocking action of a $\mathrm{Ca}^{2+}$-chelator. $A$, Hom-LTP of UL-evoked EPSPS (top) and het-LTD of WM-evoked EPSPs (bottom) induced by TBS of the UL site with (filled circles) and without (open circles) APV. The numbers of cells analyzed are indicated in parentheses at top left. $\boldsymbol{B}$, Hom-LTP of WM-evoked EPSPs (top) and het-LTD of UL-evoked EPSPs (bottom) were not induced by TBS of the WM site during the application of APV (filled circles). In the normal condition without APV, hom-LTP and het-LTD were induced (open circles). Other conventions are the same as in A. C, Hom-LTP of UL-evoked EPSPs and het-LTD of WM-evoked EPSPs were not induced by TBS of the UL site in postsynaptic CG cells into which BAPTA, a $\mathrm{Ca}^{2+}$-chelator, had been injected. Other conventions are the same as in A. D, Hom-LTP ofWM-evoked EPSPs and het-LTD of UL-evoked EPSPs were not induced by TBS of the WM site in C $G$ cells into which BAPTA had been injected. Other conventions are

in both top-down and bottom-up pathways to CG cells. As shown in Figure 5A, APV did not block hom-LTP of UL-evoked EPSPs and het-LTD of WM-evoked EPSPs after TBS of the UL site. In the eight CG cells to which APV was applied, the mean ratio of the UL-evoked EPSP slope 20-25 min after TBS to that before TBS was $1.83 \pm 0.04$ (Fig $5 A$, top). This value was not significantly different from that of nine control cells without APV $(1.74 \pm 0.04)$. Also, the mean ratio of the WM-evoked EPSP 20-25 min after TBS to that before TBS with APV $(0.68 \pm 0.02)$ was not significantly different from that without APV $(0.73 \pm$ 0.03 ) (Fig. 5A, bottom).

Different from the UL-induced hom-LTP and het-LTD, WMinduced changes were sensitive to APV (Fig. 5B). In eight APV- 

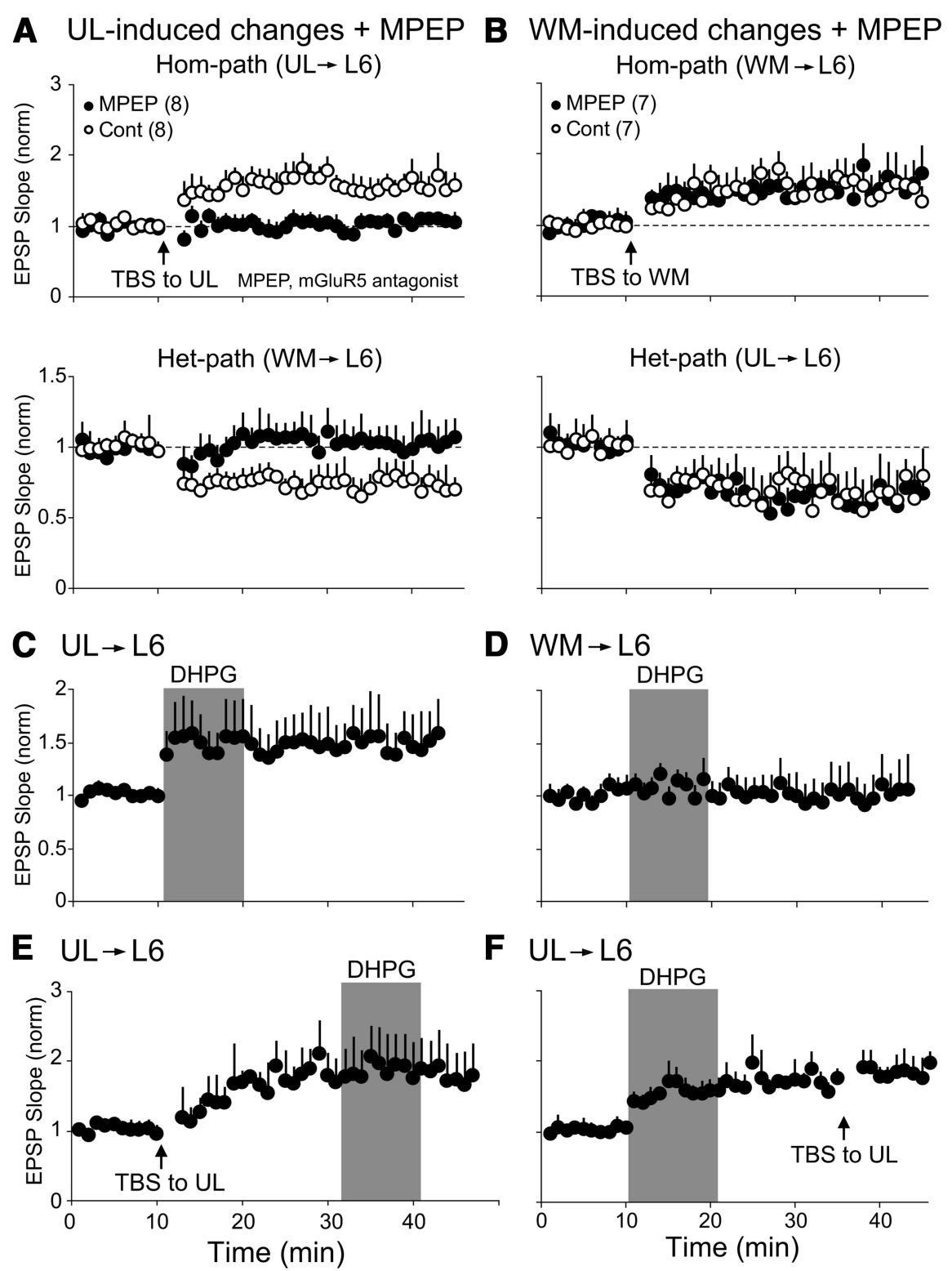

Figure 6. Involvement of mGluR5 in UL-induced synaptic plasticity. A, Hom-LTP of UL-evoked EPSPs (top) and het-LTD of WM-evoked EPSPs (bottom) were not induced by TBS of the UL site during the application of an mGluR5 antagonist, MPEP (filled circles). In the control condition without MPEP, hom-LTP and het-LTD were induced (open circles). Abscissa is the same as in $\boldsymbol{E}$. Other conventions are the same as in Figure 5A. B, Hom-LTP of WM-evoked EPSPs (top) and het-LTD of UL-evoked EPSPs (bottom) were induced by TBS of the WM site with (filled circles) and without (open circles) MPEP. Abscissa is the same as in $\boldsymbol{F}$. 0ther conventions are the same as in Figure 5A. C, A long-lasting enhancing action of an mGluR5 agonist, DHPG, on EPSPs evoked by test stimulation of the UL site. DHPG $(100 \mu \mathrm{M})$ was applied during the period indicated by shaded area. Abscissa is the same as in $\boldsymbol{E}$. D No significant action of DHPG on EPSPs evoked by stimulation of the WM site. Other conventions are the same as in $\boldsymbol{C}$. $\boldsymbol{E}, 0$ cclusion of DHPG-induced enhancement of UL-evoked EPSP by preceding TBS-induced hom-LTP. F, Occlusion of TBS-induced hom-LTP of UL-evoked EPSPs by preceding DHPG-induced enhancement of EPSPS.

treated CG cells, the mean ratio of the rising slope of WM-evoked EPSP 20-25 min after TBS of the WM site to that before TBS was $1.09 \pm 0.01$, which was significantly $(p<0.05$, unpaired $t$ test $)$ smaller than that $(1.54 \pm 0.04)$ of nine control cells without APV (Fig. 5B, top). Also, het-LTD of UL-evoked EPSPs was not induced during the APV application (Fig. $5 B$, bottom). The ratio of the rising slope of EPSP 20-25 min after TBS to that before TBS with APV was $1.00 \pm 0.01$, which was significantly $(p<0.05)$ different from the corresponding value of the nine control cells without APV $(0.54 \pm 0.01)$.
$\mathrm{Ca}^{2+}$-chelator injection into

postsynaptic cells blocks hom-LTP and het-LTD at both pathways

To test whether the rise of $\mathrm{Ca}^{2+}$ in postsynaptic sites is involved in the induction of hom-LTP and het-LTD, we injected a $\mathrm{Ca}^{2+}$-chelator, BAPTA, into postsynaptic cells through patch pipettes. As shown in Figure $5 C$, hom-LTP of UL-evoked EPSPs and het-LTD of WM-evoked EPSPs were not induced by TBS of the UL site, whereas these long-term changes were induced in control cells. In 10 CG cells into which BAPTA had been injected, the mean ratio of the UL-evoked EPSP slope 20-25 min after TBS to that before TBS was $1.03 \pm 0.02$. This value was not significantly different from the baseline value $(p>0.05)$. Also WM-evoked EPSPs were not significantly depressed by TBS of the UL site (Fig. 5C, bottom, filled circles). The mean ratio of the WM-evoked EPSP slope 20-25 min after TBS to that before TBS was $1.03 \pm 0.04$. Similarly TBS applied to the WM site did not induce significant hom-LTP in 7 BAPTA-injected cells (Fig. 5D, top, filled circles). The mean ratio of the WM-evoked EPSP slope 20-25 $\mathrm{min}$ after TBS to that before TBS was $1.04 \pm 0.02$. Also UL-evoked EPSPs were not significantly depressed (Fig. 5D, bottom, filled circles). The mean ratio of the UL-evoked EPSP slope 20-25 min after TBS to that before TBS was $0.98 \pm 0.01$.

Hom-LTP and het-LTD induced by TBS of the UL site are mGluR5-dependent, whereas those by TBS of the WM site are not

As mentioned above, UL-induced homLTP and het-LTD were not sensitive to APV. Then we tested a possibility that these UL-induced changes are sensitive to a selective blocker for metabotropic glutamate receptor of the type 5 (mGluR5), MPEP. As shown in Figure 6A, MPEP blocked the induction of hom-LTP of UL-evoked EPSPs and het-LTD of WMevoked EPSPs. The mean ratio of the ULevoked EPSPs of eight MPEP-treated cells 20-25 min after TBS to the baseline value before TBS was $1.03 \pm 0.01$, and thus hom-LTP was not induced (Fig. $6 A$, top, filled circles). Also, the ratio of WM-evoked EPSPs after TBS of the UL site to that before TBS (1.07 \pm 0.04$)$ was not significantly different from baseline value $(p>0.05)$, and thus het-LTD was not induced during the application of MPEP (Fig. $6 \mathrm{~A}$, bottom, filled circles).

In contrast to these blocking actions on the UL-induced changes, MPEP did not block hom-LTP of WM-evoked EPSPs and het-LTD of UL-evoked EPSPs after TBS of the WM site (Fig. $6 B)$. In seven MPEP-treated cells, the mean ratio of WM-evoked EPSP 20-25 min after TBS to that before TBS was $1.50 \pm 0.04$, 
which was not significantly different from the corresponding value of another seven control cells without MPEP (1.54 \pm 0.05$)$. Also, TBS of the WM site induced hetLTD of UL-evoked EPSP in the MPEPtreated cells (Fig. $6 \mathrm{~B}$, bottom). The ratio of EPSP 20-25 min after TBS to that before TBS with MPEP was $0.63 \pm 0.02$, which was not significantly different from the corresponding value of the seven control cells without MPEP $(0.67 \pm 0.02)$.

Since it was reported that mGluR1 was involved in synaptic plasticity in cortical layer VI (Wang and Daw, 2003; Rao and Daw, 2004) and hippocampal CA1 area (Volk et al., 2006), we tested effects of LY367385, a selective antagonist for mGluR1, on hom-LTP and het-LTD of EPSPs induced by TBS of the UL site, and found that this antagonist was not effective at all. In seven LY367385-treated cells, the mean ratio of UL-evoked EPSP 20-25 min after TBS of the UL site to that before TBS was $1.38 \pm$ 0.03 , which was not significantly $(p>0.05)$ different from the corresponding value of another seven control cells without the antagonist $(1.51 \pm 0.07)$. The mean ratio of WM-evoked EPSP after TBS of the UL site to that before TBS was $0.77 \pm 0.01(n=7)$, which was not significantly $(p>0.05)$ different from the corresponding value of the seven control cells $(0.72 \pm 0.03)$.

Action of an mGluR5 agonist at $\mathrm{UL} \rightarrow \mathrm{L} 6$ synapses and occlusion of TBS-induced hom-LTP

Because an mGluR5 antagonist blocked the induction of hom-LTP and het-LTD by TBS of the UL site, we then tested whether an activation of mGluR 5 affects basal synaptic transmission to CG cells from the UL and WM sites. As shown in Figure 6C, an agonist for mGluR5, (S)3,5-dihydroxyphenylglycine (DHPG) enhanced UL-evoked EPSPs. The ratio of the mean EPSP slope during the DHPG application to the preapplication value was $1.49 \pm 0.03$, which was significantly $(p<$ 0.01 ) larger than the baseline value. This enhancement lasted for the whole recording time after cessation of the DHPG application. On the other hand, DHPG was not effective for WM-evoked EPSPs (Fig. $6 D$ ). The ratio of the mean EPSP slope during the application to the baseline value was $0.97 \pm 0.02$, which was not significantly $(p>0.05)$ different from the preapplication value.

Because the mGluR5 agonist induced a long-lasting enhancement of the basal synaptic transmission of UL $\rightarrow$ L6 synapses, we then used the occlusion test to address the question of whether activation of mGluR5 is sufficient to induce hom-LTP of ULevoked EPSPs. As shown in Figure 6E, DHPG, which was applied $20 \mathrm{~min}$ after the induction of hom-LTP, did not further enhance EPSPs. There was no significant $(p>0.05)$ difference between circles).
A UL-induced changes + AM251

B WM-induced changes + AM251
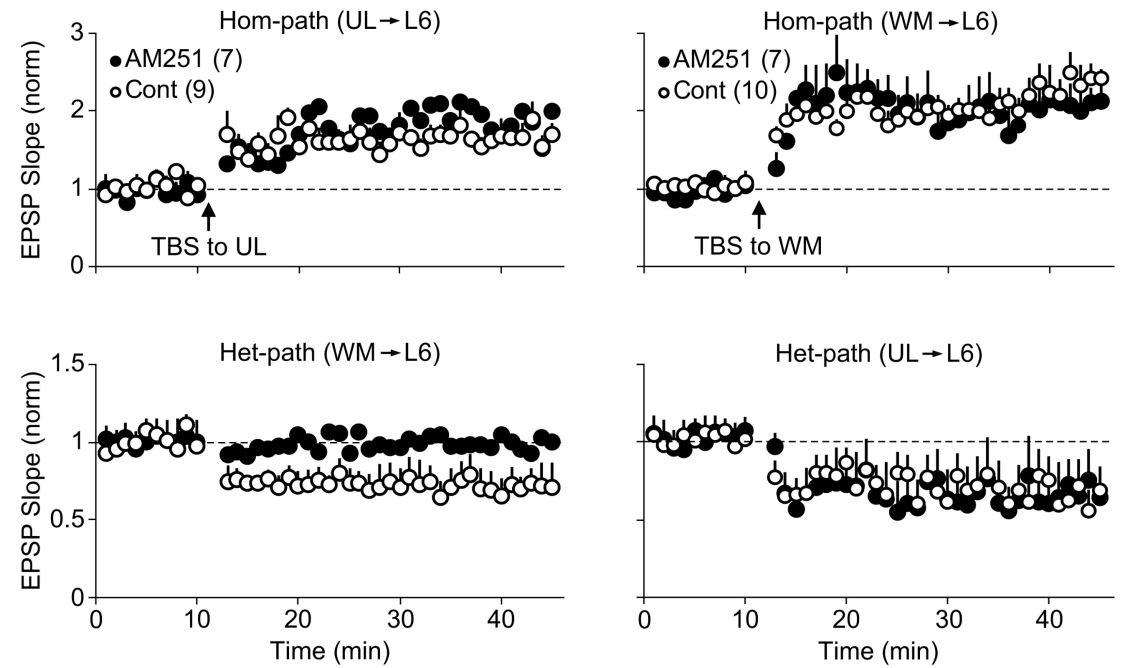

\section{CUL-induced changes in $\mathrm{CB}_{1} \mathrm{R}-\mathrm{KO}$}
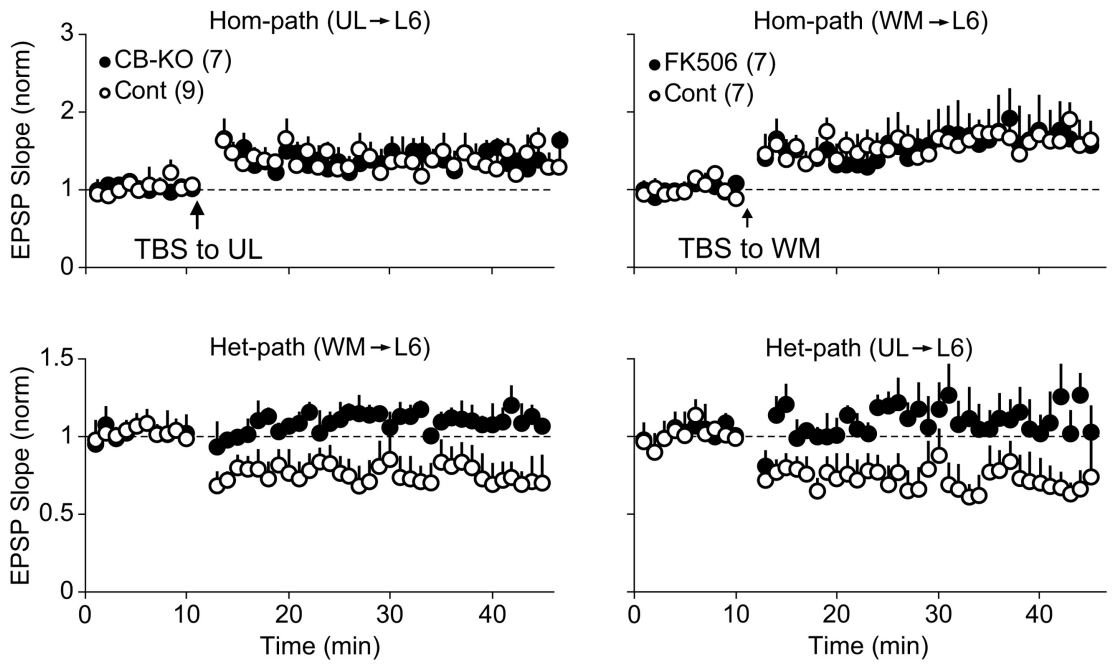

Figure 7. Involvement of endocannabinoids and calcineurin in het-LTD induced at different pathways. A, Hom-LTP of ULevoked EPSPs (top) were induced, but het-LTD of WM-evoked EPSPs (bottom) was not induced by TBS of the UL site during the application of a CB R R antagonist, AM251 (filled circles). In the control condition without AM251, het-LTD of WM-evoked EPSPs was induced (open circles). The number of cells analyzed is indicated in parentheses at top left. $\boldsymbol{B}$, Hom-LTP of WM-evoked EPSPs (top) and het-LTD of UL-evoked EPSPs (bottom) were induced by TBS of the WM site with (filled circles) and without (open circles) AM251. Other conventions are the same as in $A$. C, Induction of hom-LTP and absence of het-LTD in $\mathrm{CB}_{1} \mathrm{R}$-KO mice. Top, Hom-LTP of UL-evoked EPSPs was induced by TBS of the UL site in $\mathrm{B}_{1} \mathrm{R}$-KO mice (filled circles) and wild-type mice (open circles). Bottom, Het-LTD was not induced in $C_{1} R$ R-KO mice (filled circles), but induced in wild-type mice (open circles). $\boldsymbol{D}$, Involvement of calcineurin in WM-induced het-LTD of UL-evoked EPSPs. Hom-LTP of WM-evoked EPSPs was induced by TBS of the WM site with (filled circles) and without (open circles) a calcineurin inhibitor, FK-506 (top). Het-LTD of UL-evoked EPSPs was not induced by TBS of the WM site during the application of FK-506 (bottom, filled circles). In the normal condition without FK-506, het-LTD was induced (open

values before DHPG application and those during the DHPG application ( $1.68 \pm 0.06$ to the baseline value $5-0 \mathrm{~min}$ before the DHPG application and $1.74 \pm 0.04$ during the application). Also, TBS, which was applied $15 \mathrm{~min}$ after washout of DHPG, did not further enhance UL-evoked EPSPs (Fig. 6F). Again there was no significant difference $(p>0.05)$ between values before TBS application and those after TBS application $(1.71 \pm 0.05$ of the baseline value $5-0 \mathrm{~min}$ before TBS and $1.81 \pm 0.04$ after TBS). These results indicate that TBS-induced hom-LTP of UL-evoked EPSPs and DHPG-induced potentiation of EPSPs occluded each 
other, and the activation of mGluR5 may be sufficient for the induction of hom-LTP of UL-evoked EPSPs.

\section{Cannabinoid receptor of the type 1 is involved in het-LTD induced by TBS of the UL site}

Since $\mathrm{CB}_{1} \mathrm{R}$ was reported to be involved in het-LTD at pyramidal cells in layer II/III of the mouse visual cortex (Huang et al., 2008), we examined a possibility that $\mathrm{CB}_{1} \mathrm{R}$ is involved in het-LTD of CG cells in layer VI. During the application of an antagonist for $\mathrm{CB}_{1} \mathrm{R}$ (AM251), TBS applied to the UL site induced hom-LTP of ULevoked EPSPs of seven CG cells as in nine control cells (Fig. 7A, top). In contrast, het-LTD of WM-evoked EPSPs was not induced (Fig. 7A, bottom, filled circles). The ratio of EPSP slope 20-25 min after TBS to the pre-TBS baseline value was $0.99 \pm$ 0.01 , which was not significantly different from the baseline value. On the other hand, this antagonist did not block het-LTD of UL-evoked EPSPs following TBS of the WM site (Fig. 7B, bottom). The ratio of UL-evoked EPSPs 20-25 min after TBS of WM to the baseline value was $0.64 \pm 0.03$, which was not significantly different from the corresponding value of 10 control cells (0.69 \pm 0.03$)$.

To confirm that the loss of $\mathrm{CB}_{1} \mathrm{R}$ function leads to disappearance of het-LTD of WM-evoked EPSPs by TBS of the UL site, we tested the effect of TBS in $\mathrm{CB}_{1} \mathrm{R}-\mathrm{KO}$ mice. As shown in Figure $7 \mathrm{C}$ (bottom, filled circles), het-LTD of WM-evoked EPSPs was not induced by TBS of the UL site in CG cells of $\mathrm{CB}_{1} \mathrm{R}-\mathrm{KO}$ mice. The ratio of EPSP slope 20-25 min after TBS to the pre-TBS baseline value was $1.12 \pm 0.01$, which was not significantly $(p>0.05)$ different from the baseline value. In nine CG cells of control mice, the same parameter of TBS induced het-LTD of WM-evoked EPSPs (Fig. 7C, bottom, open circles). The ratio of EPSP slope $20-25 \mathrm{~min}$ after TBS to the pre-TBS baseline value was $0.77 \pm$ 0.03 , which was significantly $(p<0.01)$ different from the baseline value. On the other hand, hom-LTP of UL-evoked EPSPs was induced in $\mathrm{CB}_{1} \mathrm{R}-\mathrm{KO}$ as well as in wild-type mice (Fig. $7 \mathrm{C}$, top). In $\mathrm{CB}_{1} \mathrm{R}-\mathrm{KO}$ mice, the ratio of EPSP slope $20-25 \mathrm{~min}$ after TBS to the pre-TBS baseline value was $1.36 \pm 0.04$, which was not significantly different from that of nine control cells $(1.41 \pm 0.05)$.

Then we tested whether an agonist for $\mathrm{CB}_{1} \mathrm{R}$, WIN, exerts any action on UL-evoked EPSPs of CG cells in wild-type mice. As shown in Figure 8A, WIN depressed basal synaptic transmission of UL-evoked EPSPs, and thus the intensity of test stimulation was increased to the level at which the same amplitude as before the WIN application was attained, as indicated by a white arrow. Then TBS was applied to the UL site, as indicated by a black arrow. This TBS induced hom-LTP, suggesting that the agonist of $\mathrm{CB}_{1} \mathrm{R}$ does not affect the induction of hom-LTP of UL-evoked EPSPs. We then tested the action of WIN on WM-evoked EPSPs (Fig. 8B). Similar to UL-evoked EPSPs, WIN depressed the basal synaptic transmission of WM $\rightarrow$ CG synapses, and thus the intensity of test stimulation was increased in the same way as in ULevoked EPSPs. The heterosynaptic TBS was applied to the UL site, which should have induced het-LTD of WM-evoked EPSPs. As shown in Figure $8 B$ (filled circles), het-LTD was not induced when preceded by WIN-induced depression, suggesting that the depressive action of WIN occluded the induction of het-LTD of WM-evoked EPSPs. This result suggests that het-LTD of WMevoked EPSPs induced by TBS of the UL site may be mediated by endocannabinoids (Fig. 9A).

As shown in Figure 5B (bottom), the NMDA receptor antagonist prevented het-LTD of UL-evoked EPSPs from being induced by TBS of the WM site. Since $\mathrm{Ca}^{2+} /$ calmodulin-dependent protein phosphatase (calcineurin) was reported to be involved in
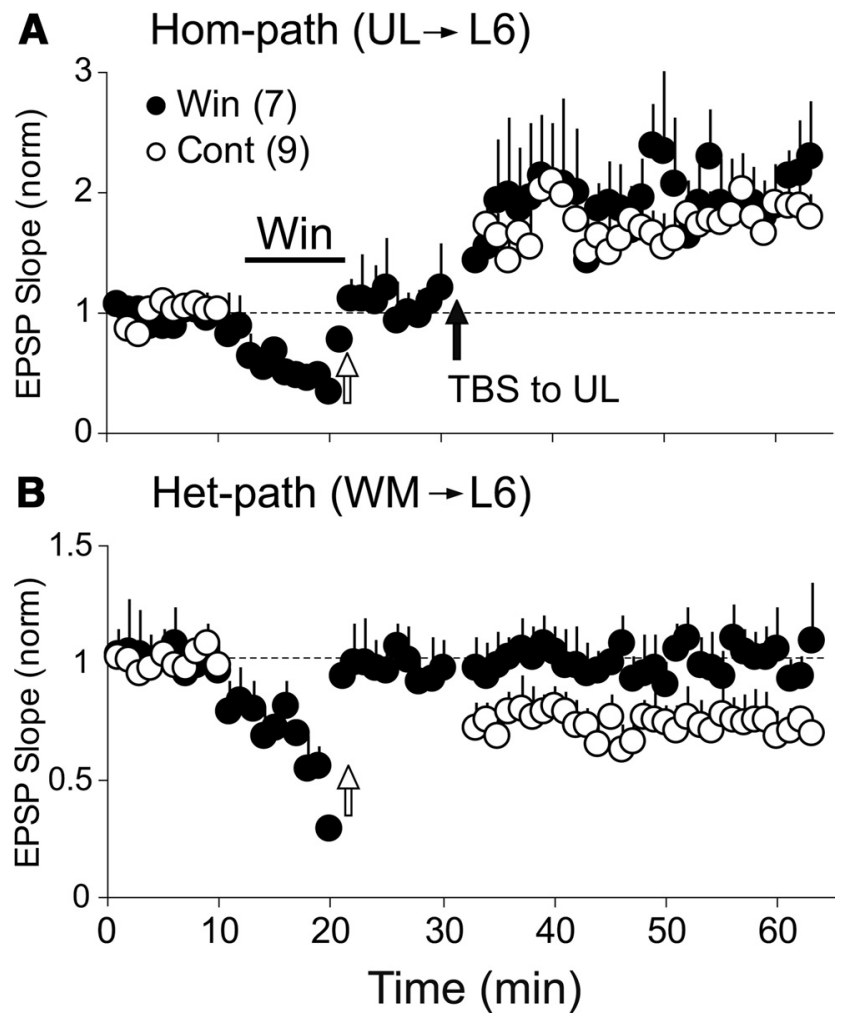

Figure 8. Suppressive action of WIN on EPSPs at both pathways and occlusion of TBSinduced het-LTD by preceding activation of $C_{1} R . A, B, C B_{1} R$ agonist WIN suppressed both UL-evoked EPSPS $(\boldsymbol{A})$ and WM-evoked EPSPS $(\boldsymbol{B})$. WIN was applied to $C$ cells through the perfusion medium during the period indicated by a horizontal line. White arrows indicate that the intensity of test shocks was increased to the level at which the original size of EPSPs was obtained. Then TBS was applied to the UL site, as indicated by a black arrow in $A$. Hom-LTP was induced at the $U L \rightarrow L 6$ synapses ( $A$, filled circles) but het-LTD was not induced at $W M \rightarrow L 6$ synapses ( $\boldsymbol{B}$, filled circles). Open circles in $\boldsymbol{A}$ and $\boldsymbol{B}$ indicate control data obtained without WIN. The other conventions are the same as in Figure $7 A$.

NMDA receptor-dependent hom-LTD in visual cortex (Torii et al., 1995), we tested the possibility that calcineurin is involved in het-LTD. Thus, we applied an inhibitor for calcineurin, FK-506, to seven CG cells. We found that het-LTD was not induced by TBS of the WM site in FK-506-treated cells (Fig. 7D, bottom, filled circles). The ratio of EPSP slope 20-25 min after TBS to the pre-TBS baseline value was $1.08 \pm 0.01$, which was significantly $(p<0.01)$ different from that of seven control cells $(0.72 \pm 0.04)$. On the other hand, hom-LTP of WM-evoked EPSPs was induced as in the control condition (Fig. $7 D$, top). The ratio of EPSP slope 20-25 min after TBS to the pre-TBS baseline value of seven FK506-treated cells was $1.70 \pm 0.05$, which was not significantly $(p>0.05)$ different from that of another seven control cells $(1.69 \pm 0.01)$.

\section{Discussion}

Pathways to layer VI CG cells from the WM and UL sites

Responses of CG cells to electrical stimulation of the WM site are possibly generated through at least two pathways: direct afferents from dLGN and recurrent collaterals of axons of other CG cells. In the rat somatosensory cortex, it was reported that the responses through the direct afferent pathway showed short latencies and paired-pulse depression, whereas those through the recurrent collateral pathway exhibited longer latencies and shortterm synaptic facilitation (Beierlein and Connors, 2002; for review, see Thomson, 2010). The present results indicating that the 
WM-evoked EPSPs had short latencies and showed paired-pulse depressions suggest that these EPSPs are generated through the direct afferent pathways from dLGN to CG cells. This seems consistent with a recent report that most layer VI cells in the mouse somatosensory and auditory cortices showed synaptic depression to repetitive stimulation of the thalamocortical pathway (Viaene et al., 2011). There is another possibility that corticofugal axons originating from layer $\mathrm{V}$ and II/III cells were activated by stimulation of the WM site and generated EPSPs through recurrent collaterals. This seems unlikely, however, because to our knowledge no reports indicate that such recurrent collateral projections to layer VI CG cells exist, although we cannot completely exclude an indirect, polysynaptic generation of EPSPs (Douglas and Martin, 2004).

In a previous study to identify the topdown projection from the upper layers to layer VI, the method of local activation with caged glutamate was applied to the rat visual cortex (Zarrinpar and Callaway, 2006). In this study, it was reported that a small proportion of layer VI pyramidal cells receive inputs from layer II/III, whereas the majority of cells receive inputs mostly from layers IV, V, and VI. A recent review stated that layers II, III, and IV would provide only small and narrowly focused excitatory inputs to layer VI (Thomson, 2010). Therefore, we cannot exclude the possibility that layer IV was also activated concomitantly with layer II/III by stimulation of the UL site. In the present study, we observed that the UL-evoked EPSPs showed longer onset latencies and slower rising and decay times than those of WM-evoked EPSPs. The long latencies of the former EPSPs may reflect the long conduction distance from the upper layer site to layer VI. The slow kinetics of the UL-evoked EPSPs implies that synapses for these EPSPs might be located at relatively distal dendrites. Nevertheless, these UL-evoked EPSPs are probably monosynaptically elicited from the upper layers because of stable responsiveness without significant jittering.

\section{Functional significance of het-LTD of synapses on CG cells in} cortical layer VI

A recent study using an optogenetic method sheds new light on the important function of CG cells in layer VI of the visual cortex. This study reports that these neurons play a role in controlling the gain of visually evoked responses of upper layer neurons through intracortical upward and corticogeniculate downward projections (Olsen et al., 2012). Of these two output projections from layer VI, the former pathway was reported to play a major role in suppressing visual responses of cortical neurons. In the present study, we have demonstrated that the major input pathways to layer VI CG cells (WM $\rightarrow$ layer VI and UL $\rightarrow$ layer VI) have the capacity of homosynaptic and heterosynaptic long-term plasticity. For example, TBS of the upward pathway from the WM induced hom-LTP of these afferent synapses and het-LTD of the other downward pathway synapses (Fig. 9B). This result suggests that strong, repetitive visual inputs from dLGN would enhance visual information transmission at the afferent synapses through LTP mechanisms so that the peripheral influence on the gain control function of layer VI neurons is enhanced. Simultaneously, het-LTD of downward synapses may weaken the top-down influence on the gain control function of CG cells in layer VI. Neurons in layer VI receive convergent inputs from a variety of brain regions, including higher cortical areas (Casagrande and Kaas, 1994; Thomson, 2010). Thus, strong visual inputs would release function of CG cells from such a top-down influence.

In case strong top-down signals through the downward pathway bombard layer VI CG cells at high frequency, such as TBS, this would induce LTP of UL $\rightarrow$ L6 synapses and LTD of $\mathrm{WM} \rightarrow$ L6 synapses (Fig. 9A). This would result in release of the function of layer VI neurons from the peripheral control from dLGN. Thus the top-down control of the CG cell function would become more effective until another series of strong visual inputs arrive at CG cells from the upward pathway. Based on these considerations, it is possible to suggest that the heterosynaptic plasticity may play a role in switching the main stream of information flow from one to the other in layer VI of the visual cortex.

Another possible functional significance of reciprocal hetLTD may be maintenance of stability of synaptic function, as reported in intercalated neurons of the guinea-pig amygdala (Royer and Paré, 2003). As pointed out in theoretical studies (Bienenstock et al., 1982; for review, see Abbott and Nelson, 2000), one-way operation of synaptic plasticity, such as homLTP, would lead to saturation of synaptic transmission efficacy. Therefore, het-LTD may be necessary for stability of synaptic 
transmission efficacy to prevent synapses receiving excessive repetitive inputs from being saturated.

\section{Roles of mGluR5 at downward pathway synapses in the induction of hom-LTP and het-LTD}

We found that an mGluR5 antagonist, MPEP, blocked the induction of hom-LTP at UL $\rightarrow$ L6 synapses while an mGluR1 antagonist, LY367385, was not effective. These findings seem inconsistent with those of Wang and Daw (2003), who previously reported that MPEP enhanced and LY367385 blocked LTP of layer VI neurons in the rat visual cortex. These discrepancies may be ascribable to the difference in animal species and/or types of cells, because they used rats and did not classify the tested neurons as CG or non-CG cells and thus their samples likely contained non-CG cells. We also confirmed that the agonist for mGluR5 enhanced UL-evoked EPSPs and this enhancement occluded TBS-induced changes. These results indicate that an activation of mGluR5 through the downward pathway is necessary for the induction of hom-LTP at UL $\rightarrow$ L6 synapses and het-LTD at $\mathrm{WM} \rightarrow$ L6 synapses (Fig. 9A). The present results suggest that this het-LTD may be due to a decrease in transmitter release from afferent presynaptic terminals from the WM site. The blockade of the het-LTD by the antagonist for $\mathrm{CB}_{1} \mathrm{R}$ further suggests that the decrease in transmitter release may be ascribable to the action of endocannabinoids. This interpretation is consistent with the view that activation of mGluRs leads to the subsequent activation of phospholipase $\mathrm{C}$, which triggers production or release of endocannabinods in co-operation with increased intracellular $\mathrm{Ca}^{2+}$ (for reviews, see Chevaleyre et al., 2006; Kano et al., 2009). Thus, it is possible to suggest that endocannabinoids may be produced in CG cells through the activation of mGluRs by TBS of the UL site and then the released endocannabinoids act on $\mathrm{WM} \rightarrow \mathrm{L} 6$ synaptic terminals (Fig. 9A). Then it is also possible that released endocannabinoids act on UL $\rightarrow$ L6 synapses, because EPSPs of these synapses were also sensitive to the $\mathrm{CB}_{1} \mathrm{R}$ agonist. Nevertheless UL $\rightarrow$ L6 synapses following TBS of the downward pathway did not show hom-LTD but rather yielded hom-LTP. This might be ascribable to strong LTP, which may overcome such endocannabinoid-mediated depression at the homosynaptic site, as suggested previously (Huang et al., 2008).

\section{Roles of NMDA receptors at upward pathway synapses in the induction of hom-LTP and het-LTD}

The present results indicate that an activation of NMDA receptors at $\mathrm{WM} \rightarrow \mathrm{L} 6$ synapses is necessary for the induction of homLTP of these upward pathway synapses and het-LTD of the downward pathway synapses (Fig. 9B). Furthermore, the results that the agonist for mGluR5 did not enhance WM-evoked EPSPs confirmed that mGluR5 is not directly involved in the afferent synaptic transmission at these synapses. The mainly postsynaptic origin of WM-induced het-LTD of UL-evoked EPSPs and its blockade by the NMDA receptor antagonist suggests that this het-LTD may be due to changes in postsynaptic receptors.

In visual cortex as well as in hippocampal CA1 area, it was suggested that calcineurin, which is activated by a moderate increase in postsynaptic $\mathrm{Ca}^{2+}$, may play a role in the induction of homosynaptic LTD (Mulkey et al., 1994; O’Dell and Kandel, 1994; Torii et al., 1995; Yasuda et al., 2003). In the present study, we also found that an inhibition of calcineurin activity by FK-506 leads to loss of het-LTD of UL-evoked EPSPs. Thus, it is likely that the rise of $\mathrm{Ca}^{2+}$ through NMDA receptor activation in CG cells may activate calcineurin, which in turn activates processes for the induction of het-LTD, although the processes down- stream of the calcineurin activation is not completely clear in the present study.

In sum, the gain controlling function of CG cells in layer VI of the visual cortex is regulated by reciprocal long-term plasticity of synapses converging from the upward and downward pathways. The operation of different molecular mechanisms in heterosynaptic depression at the two sites may help bring potentiated synapses back to the baseline or depressed level quickly and effectively avoid saturation of the same mechanisms.

\section{References}

Abbott LF, Nelson SB (2000) Synaptic plasticity: taming the beast. Nat Neurosci 3:1178-1183. CrossRef Medline

Artola A, Singer W (1987) Long-term potentiation and NMDA receptors in rat visual cortex. Nature 330:649-652. CrossRef Medline

Bear MF (2003) Bidirectional synaptic plasticity: from theory to reality. Philos Trans R Soc Lond B Biol Sci 358:649-655. CrossRef Medline

Beierlein M, Connors BW (2002) Short-term dynamics of thalamocortical and intracortical synapses onto layer 6 neurons in neocortex. J Neurophysiol 88:1924-1932. Medline

Bienenstock EL, Cooper LN, Munro PW (1982) Theory for the development of neuron selectivity, orientation specificity and binocular interaction in visual cortex. J Neurosci 2:32-48. Medline

Bourassa J, Deschênes M (1995) Corticothalamic projections from the primary visual cortex in rats: a single fiber study using biocytin as an anterograde tracer. Neuroscience 66:253-263. CrossRef Medline

Briggs F, Usrey WM (2007) A fast, receiprocal pathway between the lateral geniculate nucleus and visual cortex in the macaque monkey. J Neurosci 27:5431-5436. CrossRef Medline

Casagrande VA, Kaas JH (1994) The afferent, intrinsic and efferent connections of primary visual cortex in primates. In: Primary visual cortex in primates (Peters A, Rockland P, eds), pp 201-259. New York: Plenum.

Chevaleyre V, Takahashi KA, Castillo PE (2006) Endocannabinoidmediated synaptic plasticity in the CNS. Annu Rev Neurosci 29:37-76. CrossRef Medline

Cooke SF, Bear MF (2010) Visual experience induces long-term potentiation in the primary visual cortex. J Neurosci 30:16304-16313. CrossRef Medline

Douglas RJ, Martin KA (2004) Neuronal circuits of the neocortex. Annu Rev Neurosci 27:419-451. CrossRef Medline

Dudek SM, Friedlander MJ (1996) Developmental down-regulation of LTD in cortical layer IV and its independence of modulation by inhibition. Neuron 16:1097-1106. CrossRef Medline

Faber DS, Korn H (1991) Applicability of the coefficient of variation method for analyzing synaptic plasticity. Biophys J 60:1288-1294. CrossRef Medline

Funauchi M, Haruta H, Tsumoto T (1994) Effects of an inhibitor for calcium/calmoduli-dependent protein phosphatase, calcineurin, on induction of long-term potentiation in rat visual cortex. Neurosci Res 19: 269-278. CrossRef Medline

Gilbert CD (1983) Microcircuitry of the visual cortex. Annu Rev Neurosci 6:217-247. CrossRef Medline

Heynen AJ, Bear MF (2001) Long-term potentiation of thalamocortical transmission in the adult visual cortex in vivo. J Neurosci 21:9801-9813. Medline

Huang Y, Yasuda H, Sarihi A, Tsumoto T (2008) Roles of endocannabinoids in heterosynaptic long-term depression of excitatory synaptic transmission in visual cortex of young mice. J Neurosci 28:7074-7083. CrossRef Medline

Jiang B, Treviño M, Kirkwood A (2007) Sequential development of longterm potentiation and depression in different layers of the mouse visual cortex. J Neurosci 27:9648-9652. CrossRef Medline

Kameyama K, Sohya K, Ebina T, Fukuda A, Yanagawa Y, Tsumoto T (2010) Difference in binocularity and ocular dominance plasticity between GABAergic and excitatory cortical neurons. J Neurosci 30:1551-1559. CrossRef Medline

Kano M, Ohno-Shosaku T, Hashimotodani Y, Uchigashima M, Watanabe M (2009) Endocannabinoid-mediated control of synaptic transmission. Physiol Rev 89:309-380. CrossRef Medline

Kimura F, Nishigori A, Shirokawa T, Tsumoto T (1989) Long-term poten- 
tiation and N-methyl-D-aspartate receptors in the visual cortex of young rats. J Physiol 414:125-144. Medline

Kirkwood A, Dudek SM, Gold JT, Aizenman CD, Bear MF (1993) Common forms of synaptic plasticity in the hippocampus and neocortex in vitro. Science 260:1518-1521. CrossRef Medline

Komatsu Y, Toyama K, Maeda J, Sakaguchi H (1981) Long-term potentiation investigated in a slice preparation of striate cortex of young kittens. Neurosci Lett 26:269-274. CrossRef Medline

Lee CC, Lam YW, Sherman SM (2012) Intracortical convergence of layer 6 neurons. Neuroreport 23:736-740. CrossRef Medline

Malenka RC, Bear MF (2004) LTP and LTD: an embarrassment of riches. Neuron 44:5-21. CrossRef Medline

Mercer A, West DC, Morris OT, Kirchhecker S, Kerkhoff JE, Thomson AM (2005) Excitatory connections made by presynaptic cortico-cortical pyramidal cells in layer 6 of the neocortex. Cereb Cortex 15:1485-1496. CrossRef Medline

Mulkey RM, Endo S, Shenolikar S, Malenka RC (1994) Involvement of a calcineurin/inhibitor-1 phosphatase in hippocampal long-term depression. Nature 369:486-488. CrossRef Medline

O’Dell TJ, Kandel ER (1994) Low-frequency stimulation erases LTP through an NMDA receptor-mediated activation of protein phosphatases. Learn Mem 1:129-139. Medline

Olsen SR, Bortone DS, Adesnik H, Scanziani M (2012) Gain control by layer six in cortical circuits of vision. Nature 483:47-52. CrossRef Medline

Petrof I, Viaene AN, Sherman SM (2012) Two populations of corticothalamic and interareal corticocortical cells in the subgranular layers of the mouse primary sensory cortices. J Comp Neurol 520:1678-1686. CrossRef Medline

Petrus E, Anguh TT, Pho H, Lee A, Gammon N, Lee HK (2011) Developmental switch in the polarity of experience-dependent synaptic changes in layer 6 of mouse visual cortex. J Neurophysiol 106:2499-2505. CrossRef Medline

Rao Y, Daw NW (2004) Layer variations of long-term depression in rat visual cortex. J Neurophysiol 92:2652-2658. CrossRef Medline

Royer S, Paré D (2003) Conservation of total synaptic weight through balanced synaptic depression and potentiation. Nature 422:518-522. CrossRef Medline

Sarihi A, Jiang B, Komaki A, Sohya K, Yanagawa Y, Tsumoto T (2008) Metabotropic glutamate receptor type 5-dependent long-term potentiation of excitatory synapses on fast-spiking GABAergic neurons in mouse visual cortex. J Neurosci 28:1224-1235. CrossRef

Sillito AM, Jones HE (2002) Corticothalamic interactions in the transfer of visual information. Philos Trans R Soc Lond B Biol Sci 357:1739-1752. CrossRef Medline

Sjöström PJ, Turrigiano GG, Nelson SB (2001) Rate, timing, and cooperativity jointly determine cortical synaptic plasticity. Neuron 32:1149-1164. CrossRef Medline

Sjöström PJ, Turrigiano GG, Nelson SB (2003) Neocortical LTD via coincident activation of presynaptic NMDA and cannabinoid receptors. Neuron 39:641-654. CrossRef Medline
Smith GB, Heynen AJ, Bear MF (2009) Bidirectional synaptic mechanisms of ocular dominance plasticity in visual cortex. Philos Trans R Soc Lond B Biol Sci 364:357-367. CrossRef Medline

Sohya K, Kameyama K, Yanagawa Y, Obata K, Tsumoto T (2007) GABAergic neurons are less selective to stimulus orientation than excitatory neurons in layer II/III of visual cortex, as revealed by in vivo functional $\mathrm{Ca}^{2+}$ imaging in transgenic mice. J Neurosci 27:2145-2149. CrossRef Medline

Swadlow HA, Weyand TG (1987) Corticogeniculate neurons, corticotectal neurons, and suspected interneurons in visual cortex of awake rabbits: receptive-field properties, axonal properties, and effects of EEG arousal. J Neurophysiol 57:977-1001. Medline

Thomson AM (2010) Neocortical layer 6, a review. Front Neuroanat 4:13. CrossRef Medline

Thomson AM, Bannister AP (2003) Interlaminar connections in the neocortex. Cereb Cortex 13:5-14. CrossRef Medline

Torii N, Kamishita T, Otsu Y, Tsumoto T (1995) An inhibitor for calcineurin, FK506, blocks induction of long-term depression in rat visual cortex. Neurosci Lett 185:1-4. CrossRef Medline

Tsumoto T (1992) Long-term potentiation and long-term depression in the neocortex. Prog Neurobiol 39:209-228. CrossRef Medline

Tsumoto T, Suda K (1980) Three groups of cortico-geniculate neurons and their distribution in binocular and monocular segments of cat striate cortex. J Comp Neurol 193:223-236. CrossRef Medline

Tsumoto T, Creutzfeldt OD, Legéndy CR (1978) Functional organization of the corticofugal system from visual cortex to lateral geniculate nucleus in the cat (with an appendix on geniculo-cortical mono-synaptic connections). Exp Brain Res 32:345-364. Medline

Updyke BV (1975) Patterns of projection of cortical areas 17, 18, and 19 onto laminae of dorsal lateral geniculate nucleus in cat. J Comp Neurol 163:377-395. CrossRef Medline

Viaene AN, Petrof I, Sherman SM (2011) Synaptic properties of thalamic input to the subgranular layers of primary somatosensory and auditory cortices in the mouse. J Neurosci 31:12738-12747. CrossRef Medline

Volk LJ, Daly CA, Huber KM (2006) Differential roles for group I mGluR subtypes in induction and expression of chemically induced hippocampal long-term depression. J Neurophysiol 95:2427-2438. Medline

Wang XF, Daw NW (2003) Long term potentiation varies with layer in rat visual cortex. Brain Res 989:26-34. CrossRef Medline

Yasuda H, Higashi H, Kudo Y, Inoue T, Hata Y, Mikoshiba K, Tsumoto T (2003) Imaging of calcineuin activated by long-term depressioninducing synaptic inputs in living neurons of rat visual cortex. Europ J Neurosci 17:287-297. CrossRef

Zarrinpar A, Callaway EM (2006) Local connections to specific types of layer 6 neurons in the rat visual cortex. J Neurophysiol 95:1751-1761. CrossRef Medline

Zimmer A, Zimmer AM, Hohmann AG, Herkenham M, Bonner TI (1999) Increased mortality, hypoactivity, and hypoalgesia in cannabinoid CB1 receptor knock-out mice. Proc Natl Acad Sci U S A 96:5780-5785. CrossRef Medline 